\title{
Paciência com a ciência
}

\author{
Be patient with science
}

Edson Khodor Cury*

Lembro-me bem quando, há exatos 22 anos, em uma de suas magníficas aulas ao $4^{\circ}$ ano médico da Escola Paulista de Medicina, o Prof. Dr. José Pinus nos apresentou uma doença fascinante: a Estenose Hipertrófica do Piloro (EHP). Ensinava-nos o mestre que se tratava de uma afecção cuja fisiopatologia podia ser facilmente compreendida e que seu tratamento cirúrgico era simples, eficiente e consagrado desde $1907^{1}$. De fato, qual a dificuldade em se compreender que a hipertrofia progressiva da musculatura do piloro gastroduodenal resultaria em mau esvaziamento gástrico, traduzido clinicamente por vômitos não biliosos e progressivos? $\mathrm{E} \mathrm{o}$ tratamento cirúrgico então, de fácil execução técnica, pouco agressivo, que consistia simplesmente na secção do músculo pilórico hipertrofiado. O que me inquietou na época foi a referência de que, apesar de esta patologia ter sido primeiramente descrita por Hirschsprung em 1887, sua etiologia permanecia incerta.

Alguns anos após, tornei-me um cirurgião pediatra e tive oportunidade de tratar com êxito vários casos de EHP. Passei então a acompanhar de perto o esforço da ciência na tentativa de elucidar a etiologia desta curiosa afecção.

Uma das primeiras tentativas para explicar a doença foi o reconhecimento de sua maior incidência familiar, sem que se identificasse, entretanto, sua associação com fatores genéticos.

A hipergastrinemia no recém-nascido foi apontada por alguns pesquisadores como fator causal, embora sua participação na doença parecia muito mais conseqüência da obstrução pilórica do que a causa em si 2,3 .

A partir da década de 50 descreveram-se alterações morfológicas da inervação intrínseca e de células ganglionares do piloro tais como imaturidade, degeneração ou ainda distribuição anormal ${ }^{4-6}$. Estudos imunoistoquímicos posteriores revelaram não haver imaturidade, tampouco degeneração das células ganglionares. Por outro lado, a mesma imunoistoquímica identificava diminuição no número de células gliais mioentéricas (células de sustentação do sistema nervoso $)^{7}$. Esse fenômeno provocaria um retardo na estimulação elétrica, podendo ser causa da hipertrofia pilórica.

Já na década de 80 o avanço tecnológico possibilitou o reconhecimento dos peptídeos gastrintestinais. Parecia que

* Professor Adjunto da UNIFESP/EPM, São Paulo. a etiologia da EHP estava finalmente solucionada quando, em 1986, pesquisadores demonstraram a diminuição das fibras neurais específicas para o peptídeo vaso-ativo intestinal (VIP). Como o VIP está envolvido no relaxamento da musculatura lisa do trato gastrintestinal, esses achados nos colocavam, aparentemente, muito próximos da descoberta final.

Uma década após, vários trabalhos mostraram a ação sinérgica do óxido nítrico $(\mathrm{ON})$ com o VIP. O óxido nítrico aparecia como um potente neurotransmissor não colinérgico, não adrenérgico envolvido na inervação inibitória da musculatura lisa do trato gastrintestinal ${ }^{8,9}$. Sua responsabilidade na gênese da EHP passou, então, a ser cada vez mais fundamentada por experimentos científicos. Através do bloqueio da síntese do ON, os pesquisadores observaram, entre outras alterações, a hipertrofia da camada muscular do piloro ${ }^{10}$.

$\mathrm{Na}$ verdade, perto de 2.000 publicações de estudos experimentais, auxiliados pela engenharia genética, têm demonstrado a participação do óxido nítrico em diversos fenômenos da fisiologia humana. O Brasil, é claro, não poderia ficar à margem dessas descobertas. Neste número do Jornal de Pediatria somos brindados com um estudo experimental, de altíssimo nível científico, conduzido pelo Prof. Irnak Barbosa e colaboradores. Trata-se de tema atual e palpitante, de metodologia relativamente simples, mas que nos revela com clareza as conseqüências do bloqueio da síntese do ON sobre o trato disgestório, notadamente sobre o piloro gastroduodenal. É curioso notar que o bloqueio da síntese do ON na gestação de ratos causou também desnutrição intra-útero, fenômeno que não é uniformemente encontrado em crianças com EHP. Conforme nos ensinam os autores, se o bloqueio da síntese do $\mathrm{ON}$ não for o único responsável pela hipertrofia pilórica, é provavelmente o elemento central deste processo.

Hoje, 114 anos após sua identificação como entidade clínica, explica-se aos alunos do $4^{\circ}$ ano médico que a etiologia da EHP continua desconhecida e que provavelmente seja multifatorial. Porém, graças aos avanços da biologia molecular estamos, sem dúvida, cada vez mais próximos de descobrir o que causa a hipertrofia da musculatura pilórica exclusivamente no período neonatal.

O histórico da EHP presta-se para mostrar-lhes que apenas com tenacidade e paciência a ciência consegue explicar os fenômenos mais incríveis que observamos na prática clínica diária. 
O histórico da EHP presta-se para mostrar-lhes que apenas com tenacidade e paciência a ciência consegue explicar os fenômenos mais incríveis que observamos na prática clínica diária.

\section{Referências bibliográficas}

1. Dufour H; Fredet P. La stenose hypertrophique du pylore chez le nourrison et son traitement chirurgical. Revue de Chirurgie 1908; 37:208.

2. Spitz L, Zail SS. Serum gastrin levels in congenital hypertrophic stenosis. J Pediatr Surg 1976; 11:33.

3. Janik JS, et al. The role of gastrin in congenital hypertrophic pyloric stenosis. J Pediatr Surg 1978; 13:151.

4. Belding HH, Kernohan JW. A morphologic study of the myenteric plexus and musculature of the pylorus. Surg Gynecol Obstet 1953; 97:322
5. Friensen SR, Boley J, Miller DR. The myenteric plexus of the pylorus: its early normal development and its changes in hypertrophic pyloric stenosis. Surgery 1956; 39:21.

6. Spitz L, Kaufmann JCE. The neuropathological changes in congenital hypertrophic pyloric stenosis. South African J Surg $1975 ; 13: 239$.

7. Kobayashi H, O’Brian DS, Puri P. Selective reduction in intramuscular nerve supporting cells in infantile hypertrophic pyloric stenosis. J Pediatr Surg 1994; 29:651.

8. Furchgott RF, Zawadzki JV. The obligatory role of endothelial cells in the relaxation of arterial smooth muscle by acetylcholine. Nature 1980; 228:373.

9. Ignarro LJ, et al. Activation of purified soluble guanylate cyclase by endothelium derived relaxing factor from intrapulmonary bradykinin and arachidonic acid. J Pharmacol Exp Ther 1986; 237:893.

10. Voelker CA, et al. Perinatal nitric oxide synthase inhibition retards neonatal growth by inducing hypertrophic pyloric stenosis in rats. Pediatric Research 1995; 38:768.

\title{
Um "experimento natural" de mortalidade de recém-nascidos de muito baixo peso
}

\section{A "natural experiment" regarding the mortality of very low birth weight infants}

\author{
Renato Machado Fiori*
}

O estudo publicado nesta edição do Jornal de Pediatria pelo Dr. Fernando Barros sob o título "Atención de Salud en Niños de Muy Bajo Peso al Nascer en Montevideo" aborda a questão da qualidade do tratamento intensivo neonatal público e privado em Montevidéu.

A comparação da qualidade da assistência perinatal em diferentes hospitais através da análise de resultados é praticamente inviabilizada pelas grandes diferenças das populações estudadas. Condições prévias de saúde materna, nível socioeconômico, graus de complexidade assistencial dos hospitais e tipos de pacientes referidos introduzem vieses que as mais complexas análises estatísticas quase nunca conseguem superar. Entretanto, utilizando-se de uma circunstância especial de possibilidade de transferência de crianças nascidas em hospitais públicos para hospitais privados em Montevidéu, o autor conseguiu mimetizar um modelo experimental, comparando dois grupos de recém-nascidos de muito baixo peso, cujas mães provinham do mesmo sistema assistencial, os quais foram alocados, supostamente ao acaso, para receber tratamento

\footnotetext{
* Prof. Titular de Pediatria da FAMED da PUCRS. Chefe do Serviço de Neonatologia do Hospital São Lucas da PUCRS.
}

intensivo ou num hospital público ou num hospital privado. De alguma forma, este modelo lembra o célebre "experimento natural" de John Snow, no século XIX, em Londres, o qual, aproveitando-se do fato de que uma companhia fornecedora de água, ao contrário de outra, passara a retirar água do Rio Tâmisa antes que este atravessasse a cidade, comparou a prevalência de cólera nas populações servidas pelas duas companhias, concluindo que a epidemia devia-se à contaminação do rio ao atravessar a cidade ${ }^{1-2}$

Deve-se salientar que esta possibilidade de transferência de recém-nascidos do sistema público de saúde para o sistema privado oferecida pela cidade de Montevidéu é pouco comum na América Latina.

Os recém-nascidos enviados aos hospitais privados tinham características que sugeriam maior risco de morte. Eram mais imaturos, receberam menos corticóide pré-natal e tiveram Apgar mais baixo aos 5 minutos de vida; necessitaram na sala de partos mais vezes oxigênio, ventilação com máscara e intubação endotraqueal. O autor aparentemente não conseguiu coletar dados para estabelecer um índice prognóstico, como o CRIB, o qual ajudaria a definir melhor a perspectiva de desfecho de cada um dos grupos. 